\title{
Water migration of Chernobyl radionuclides in rivers of Belarus
}

\author{
O. Zhukova, E. Shagalova and N. Shiryaeva
}

\author{
The State Committee for Hydrometeorology, The Republican Centre of Radiation \\ and Environment Monitoring, 220023 Minsk, Belarus
}

\begin{abstract}
The analysis of formation of radioactive contamination of rivers of Belarus, entering the Dnieper basin (Dnieper, Sozh, Iput, Besed, Pripyat), after the accident at the ChNPP is given in the paper. The legitimacies and features of behaviour of Chernobyl radionuclides in surface waters are detected. The total runoff of ${ }^{137} \mathrm{Cs}$ by the main rivers Sozh (Gomel), Dnepr (Rechitsa), Pripyat (Mozyr), Iput (Dobrush), Besed (Svetilovitchi) for the period 1987-2000 is submitted. The peculiarities of carrying out the monitoring at the experimental watershed of the Iput' river (the Dnieper-Sozh basin), flowing through the Byelorussian-Bryansk «caesium» spot, are described. The conceptual and mathematical models of radionuclide migration in the river network is suggested. The calculations have been conducted and the analysis of the experimental and calculated data on transport of radioactive contamination have been carried out. The prognosises of distribution of radioactive contamination in the rivers of Belanus (for example the Iput river basin) are obtained. The reliability of forecasting results of radionuclide behaviour in the rivers is confirmed by the data received on the network of radiation monitoring.
\end{abstract}

\section{INTRODUCTION}

The hydrosphere plays an important role in the transfer of radioactive contamination from the places of ejection into the environment and further to a man. The river systems are the most moving parts of the hydrosphere. They favour more dynamic (after the atmospheric transfer) distribution of radioactive contamination during accidental ejection.

As a result of the accident at the ChNPP a huge amount of radionuclides was ejected into the environment. Those ejections had wide regional character and spread in the whole Eastern and Western Europe. Besides, the greatest amount of radionuclides fell out on the territory of Belarus. In Belarus $23 \%$ of the territory was contaminated by ${ }^{137} \mathrm{Cs}$ with the levels from $37 \mathrm{kBq} / \mathrm{m}^{2}$ up to $1480 \mathrm{kBq} / \mathrm{m}^{2}$ and more, with the total area of 46.45 thousand $\mathrm{km}^{2}$ where more than 3600 settlements are located. The main part of radioactive fallouts was concentrated on the watershed territory of the rivers Dnieper, Pripyat and their tributaries. Just these very territories are and will remain for many years the potential landscape sources of formation of radioactive runoff into the Dnieper-Sozh system, and the surface water - the main transport system of the radionuclides.

During the initial period after the accident at the ChNPP the level dynamics of radioactive contamination was stipulated by radioactive fallouts on water objects, by physico- chemical properties of aerosols and by hydrology. From the end of May, 1986 the direct fallouts on water objects have stopped, and during the next years (for long-lived radionuclides) their concentration are determined mainly by secondary processes: washout from the contaminated watersheds, access with ground-water, wind carry from the contaminated dry land places on a water surface, interaction with bottom sediments. The processes of radioactive contamination runoff by rain water and melt-water into the river basins are considered to be the most dynamical, long-term and dangerous.

The processes of radioactive contamination transfer into the river systems are carried out in the dissolved form, on suspensions and transported by drifts, which contribution to the common runoff depends on the kind of radionuclide, its physico-chemical properties, and also on hydrological and hydromorphometrical characteristics of a river bed. In bottom sediments on a river bed, in stagnant zones at dams, in reservoirs radionuclides are accumulated due to sedimentation of microdispersed particles of suspended drifts, thus creating moving local centers of high concentration. 
At present and in the next decades ${ }^{137} \mathrm{Cs},{ }^{90} \mathrm{Sr}$ and also plutonium isotopes make and will make the main contribution into radioactive contamination of the environment.

In water courses and in reservoirs with running water the concentration of radionuclides is gradually decreased. At the same time in closed reservoirs and in the places of erosive material accumulation in the local negative structures of the hydrographic network and in closed falls of the relief such as lakes, ponds and reservoirs, the rise of radioactive concentration is observed. As a result of this the formation of zones of secondary surface water contamination occurs. This is particularly dangerous in the places where accumulation zones and areas of water-bearing horizon supply overlap [1].

\section{RESULTS AND DISCUSSIONS}

\subsection{Results of radiation monitoring on the rivers of Belarus}

The data of radiation monitoring of water objects in Belarus show that the radiation situation on the rivers of the Dnieper-Sozh and Pripyat basins was stabilised, the annual average concentration of ${ }^{137} \mathrm{Cs}$ during the period of observation 1987-2000 in large and medium rivers of Belarus have notably decreased. The exceeding of the National Permissible Level-99 (in drink water for ${ }^{137} \mathrm{Cs}-10 \mathrm{~Bq} / 1$ and for ${ }^{90} \mathrm{Sr}-0,37 \mathrm{~Bq} /$ ) in water of the rivers was not observed (tabl. 1).

The data analysis of ${ }^{137} \mathrm{Cs}$ contents during spring high water of 1999 in the basin of Pripyat river (in Mozyr) showed, that ${ }^{137} \mathrm{Cs}$ concentration in the soluble form have remained at the average values level of concentration for given sampling site for the previous years (1996-1998). However, radionuclide concentrations on the suspensions have considerably increased, this testifies that at present this radionuclide is washed out by floodwater and is transferred in the greater degree with hard material from the river watershed. The similar results on ${ }^{137} \mathrm{Cs}$ transfer into the river network on hard particles at high waters were obtained in Ukraine [2].

At present there is a distinct tendency to decrease ${ }^{137} \mathrm{Cs}$ drift by the rivers (tabl.1). The total ${ }^{137} \mathrm{Cs}$ drift by the rivers of Belarus for the period 1987-1999 has made for: the river Sozh (in Gomel) $-2.4 \cdot 10^{13}$ $\mathrm{Bq}$, the Dnieper (in Rechitsa) $-1.7 \cdot 10^{13} \mathrm{~Bq}$, the Pripyat (in Mozyr) $-1.3 \cdot 10^{13} \mathrm{~Bq}$, the Iput (in Dobrush)$0.91 \cdot 10^{13} \mathrm{~Bq}$, the Besed (in Svetilovitchi) $-0.19 \cdot 10^{13} \mathrm{~Bq}$. From the total sum of ${ }^{137} \mathrm{Cs}$ activity which bes been transferred by each river for 12 years (1987-1999), 85\% has been transferred by the Iput for 2 years, $81 \%$ of activity has been transferred by the Sozh for 3 years, by Besed - for 4 years, by Pripyat - for 6 years and $71 \%$ of activity has been transferred by the Dnieper for 9 years. The comparison of ${ }^{137} \mathrm{Cs}$ dift for the period 1987-1993 on the Dnieper and Pripyat within Ukrain and on the hydroposts of Belans shows that only $26 \%$ from the total ${ }^{137} \mathrm{Cs}$ drift was formed in $30-\mathrm{km}$ zone of the ChNPP. Thus, the contribution of large watershed areas with low levels of radioactive contamination into the formation of the river runoff has more influence on the secondary contamination than the surface washoff from a very contaminated territories but with relatively small watershed areas [3].

The decrease of ${ }^{137} \mathrm{Cs}$ drift occurred irrespective to the oscillation of water amount. The share of ${ }^{137} \mathrm{Cs}$ transported by suspensions has increased from $29 \%$ in 1987 up to $47 \%$ in 1991 . And, though, the data of monitoring show the stabilization of this ratio for the last years - more probable is ${ }^{137} \mathrm{Cs}$ runoff into the bed network during high waters mainly on hard particles, instead of in the dissolved form. The results of casual observations of the Ukrainian Hydrometeorological Reserch Institution on the rivers Pripyat and Dnieper and observation, held by the Republican Centre of radiation control and environment monitoring on the Iput, show that the greater part of ${ }^{137} \mathrm{Cs}$ in 1994-1995 was transported by suspended drifts $(50-60 \%)$ [4].

The data analysis of surface water contamination levels by ${ }^{90} \mathrm{Sr}$ of the rivers of the Dnieper-Soath watershed shows the increased levels of this radionuclide in the river Besed in comparison with other inspected rivers.

The dynamics of ${ }^{90} \mathrm{Sr}$ drift through the river sampling site shows that this radionuclide migrate mainly in a soluble state and is in instant dependence with the amount of water in the river. The total ${ }^{99} \mathrm{Sr}$ drift by the rivers of Belarus for the period 1990-1998 has made: the Sozh (Gomel) $-2,9 \cdot 10^{12} \mathrm{~Bq}$, the 
Dnieper (Rechitsa) - 2,7 $\cdot 10^{12} \mathrm{~Bq}$, the Pripyat (Mozyr) - 3,7 $\cdot 10^{12} \mathrm{~Bq}$, the Iput (Dobrush) $-0,8 \cdot 10^{12} \mathrm{~Bq}$, the Besed (Svetilovitchi) $-0,7 \cdot 10^{12} \mathrm{~Bq}$.

The process of redistribution of radioactive contamination on the beds of rivers, reservoirs, lakes is traced more distinctly against the continuing decrease of radionuclide transfer.

Table 1. Annual average concentrations $\left(\hat{\mathrm{C}}, \mathrm{Bq} / \mathrm{m}^{3}\right)$ and drift $\left(\mathrm{Q}, \times 10^{11} \mathrm{~Bq}\right)$ of ${ }^{137} \mathrm{Cs}$ in the rivers of Belarus in the rivers of Belanus for the period 1987-2000 years

\begin{tabular}{|c|c|c|c|c|c|c|c|c|c|c|}
\hline River & \multicolumn{2}{|c|}{$\begin{array}{c}\text { Dnieper } \\
\text { (Rechitsa) }\end{array}$} & \multicolumn{2}{|c|}{ Pripyat' (Mozyr) } & \multicolumn{2}{|c|}{$\begin{array}{c}\text { Sozh } \\
\text { (Gomel) }\end{array}$} & \multicolumn{2}{|c|}{$\begin{array}{c}\text { Iput' } \\
\text { (Dobrush) }\end{array}$} & \multicolumn{2}{|c|}{$\begin{array}{c}\text { Besed } \\
\text { (Svetilovichi) }\end{array}$} \\
\hline $\begin{array}{l}\text { Average dencity } \\
\text { of watershed }\end{array}$ & \multicolumn{2}{|c|}{89,9} & \multicolumn{2}{|c|}{51,1} & \multicolumn{2}{|c|}{148,0} & \multicolumn{2}{|c|}{155,1} & \multicolumn{2}{|c|}{370,0} \\
\hline Years & $\hat{\mathrm{C}}$ & $\mathrm{Q}$ & $\hat{C}$ & $\mathbf{Q}$ & $\hat{\mathrm{C}}$ & $\mathbf{Q}$ & $\tilde{\mathrm{C}}$ & $\mathrm{Q}$ & $\hat{\mathrm{C}}$ & $Q$ \\
\hline 1987 & 266 & 34 & 281 & 28,1 & 1565 & 100 & 2301 & 48 & 688 & 8,5 \\
\hline 1988 & 211 & 23 & 170 & 22,8 & 851 & 53 & 1454 & 27 & 374 & 3,7 \\
\hline 1989 & 126 & 19 & 159 & 23,7 & 303 & 22 & 370 & 4,4 & 178 & 1,5 \\
\hline 1990 & 59 & 7,7 & 56 & 7,4 & 159 & 11 & 455 & 3,7 & 100 & 0,74 \\
\hline 1991 & 67 & 7,2 & 48 & 7 & 141 & 9,3 & 174 & 1,9 & 96 & 0,56 \\
\hline 1992 & 52 & 4,8 & 46 & 7,8 & 74 & 4,1 & 139 & 1,5 & 89 & 0,56 \\
\hline 1993 & 48 & 4,8 & 33 & 5,4 & 78 & 5,3 & 136 & 1,9 & 89 & 0,74 \\
\hline 1994 & 50 & 9 & 41 & 5,9 & 60 & 6 & 64 & 1,8 & 59 & 0,8 \\
\hline 1995 & 44 & 4,7 & 41 & 3,9 & 48 & 3 & 92 & 1,4 & 51 & 0,54 \\
\hline 1996 & 39 & 2,6 & 24 & 2,5 & 34 & 1,4 & 37 & 0,3 & 33 & 0,13 \\
\hline 1997 & 34 & 3,25 & 31 & 3,2 & 23 & 1,14 & 37 & 0,36 & 23 & 0,13 \\
\hline 1998 & 13 & 2,12 & 13 & 2,9 & 25 & 2,3 & 47 & 0,97 & 20 & 0,21 \\
\hline 1999 & 10 & 1,3 & 17 & 3,7 & 19 & 1,4 & 39 & 1,19 & 9 & 0,24 \\
\hline 2000 & 16 & & 15 & & 22 & & 71 & & 22 & \\
\hline
\end{tabular}

The studies of the bottom sediments of the rivers of the Dnieper and Pripyat basins allow to find radiation dangerous places of radionuclides accumulation in the bottom sediments along the bed of the rivers and reservoirs. Reservoirs, backwaters, less lotic parts of the rivers are the accumulators of ${ }^{137} \mathrm{Cs}$ in the bottom sediments.

Practically on the whole part of the river Nizhnyaiya Braginka near the village Gden and below ${ }^{137} \mathrm{Cs}$ contamination levels of the bottom sediments in 23.08 .2000 were $49760,38135,30590,12940,14340$ $\mathrm{Bq} / \mathrm{kg}$. Thus, they can be classified as a hard radioactive waste $(9630 \mathrm{~Bq} / \mathrm{kg})$. In the reservoir in front of Dobrush dam in $15.10 .1992{ }^{137} \mathrm{Cs}$ contamination levels of the bottom sediments were from 11400 up to $83600 \mathrm{~Bq} / \mathrm{kg}$. On the other parts of the Iput and Besed beds on the territory of Belarus ${ }^{137} \mathrm{Cs}$ contamination of the bottom sediments is on the level of radioactive waste $963 \mathrm{~Bq} / \mathrm{kg}$ and more. Thus, in the result of ${ }^{137} \mathrm{Cs}$ washout from the watershed territories of the rivers with a hard runoff occurs ${ }^{137} \mathrm{Cs}$ accumulation in the bottom sediments of rivers and reservoirs.

The study of radionuclide accumulation in the bottom sediments shows that at present the maximum concentration is largely caused by washing-off of radioactive contamination from the water catchment with suspended particles and further transfer along the river bed with the transported drift as well as by exchange processes in the water-bottom-sediments and suspension-water systems.

The high concentration of mobile ${ }^{137} \mathrm{Cs}$ forms were found in the bottom sediments in some parts of the river Iput. The high concentration in the bottom sediments of the forms, which can exchange in the bottom-sediments-water system, is a potential danger of the secondary contamination of the rivers.

${ }^{137} \mathrm{Cs}$ transfer with suspended and carried drifts, which contribution to the total radionuclide runoff rises with the times, influences greatly ${ }^{137} \mathrm{Cs}$ migration. The importance of the conclusion is that in the result of non-stationarity of the processes in the river bed occurs the sedimentation of the suspended drifts in the parts with slow river flow. All this favours the creation of the local moving ecologically dangerous centres of radionuclide accumulation in the bottom sediments of flood-plain lands, shallows, reservoirs. 
Such centres are the sources of the secondary contamination of the surface water and demand regular monitoring and water saving measures.

The analysis of formation of river contamination in Belarus, using as an example experimental water catchment of the Iput, shows that the most intensive radionuclide runoff from the water catchment territories is taken place in the upper reaches of the Dnieper basin (its tributaries the Iput and Sozh).

\subsection{Mathematical model of radionuclide transfer by river}

On the basis of data of surface water radiation monitoring, the model for forecasts of radionuclides behaviour in the river system was developed. There is a flow chart of radionuclide transfer in the river system on Fig.1.

The sources of radioactive contamination of water objects are as follows:

1) direct aerosol fallout on water surface;

2) radionuclide accession from contaminated territories of water catchments with water runoff and with soil particles;

3) local radionuclide accession with contaminated water of the tributaries.

For modelling of radioactive contamination spread in the river system was chosen a chamber model which needs minimum input for realisation. According to this model the river system is divided into Nsuccessive chambers, each of them includes two interactive layers: high layer $V_{w}$ which contains water and suspended drifts and low layer with the volume $V_{b}$ - active layer of bottom sediments. Between these components there are: sedimentation- stirring-up of suspended macroparticles, sorption-desorption connected with the processes in the water-bottom-sediments and suspension-water systems.

The processes on the river part are explained by common system of differential equations of conservation of water mass, suspended and carried drift concentrations and radionuclide runoff in soluble and suspended form which are average according to the chamber size. Here is studying the quasistationary migration model with equilibrium chemical conditions of interaction with suspended and bottom drifts. This demands the input of following suggestions:

1) water discharge in tested volumes of the river is constant;

2) representative nunoff time from water catchment is much more than the time of water change in the river;

3) sorption equilibrium between water and suspension, water and bottom sediments reaches immediately for change forms;

4) equilibrium between stirring-up and sedimentation processes is attained quickly;

5) bottom sediments discharge is constant.

For this particular stage of research there are three cases.

- Radionuclide access in the entrance river site during limited and unlimited time period.

- Radionuclide fallout onto the water surface of the whole river or onto some parts.

- Radionuclide access into the river system with surface runoff from contaminated water catchment (or from some parts).

The worked out model allows to make following estimations: radionuclide concentration in soluble form, on suspensions and with bottom sediments; radionuclide transfer though the control river site; coefficient of hard and liquid runoff of radionuclides into the river system.

The forecast estimations of radioactive contamination of the surface water (the rivers of Belarus) can be made during the local radionuclide access into the river system as well as during accidental radionuclide fallout onto the water surface.

The test of the model of radioactive contamination transfer by river was made on the basis of the data, obtained on the experimental water catchment of the river Iput. The working efficiency of the model was tested by a range of calculation experiments for studying of radioactive contamination spread along the whole bed of the Iput [5].

Was made the comparison of full-scale measurements, held for ten years 1987-1997, and of the calculation results of the concentration in the water, on suspensions and in bottom sediments, which were referred to the last sampling site (Dobrush). The calculations were made for hydraulically constant 
conditions for the whole time range. The major part of calculation points is within the range of maximum and minimum annual values of experimental data. The agreement of experimental and calculated data for the Iput allows to make a conclusion that the model passed the test satisfactory.

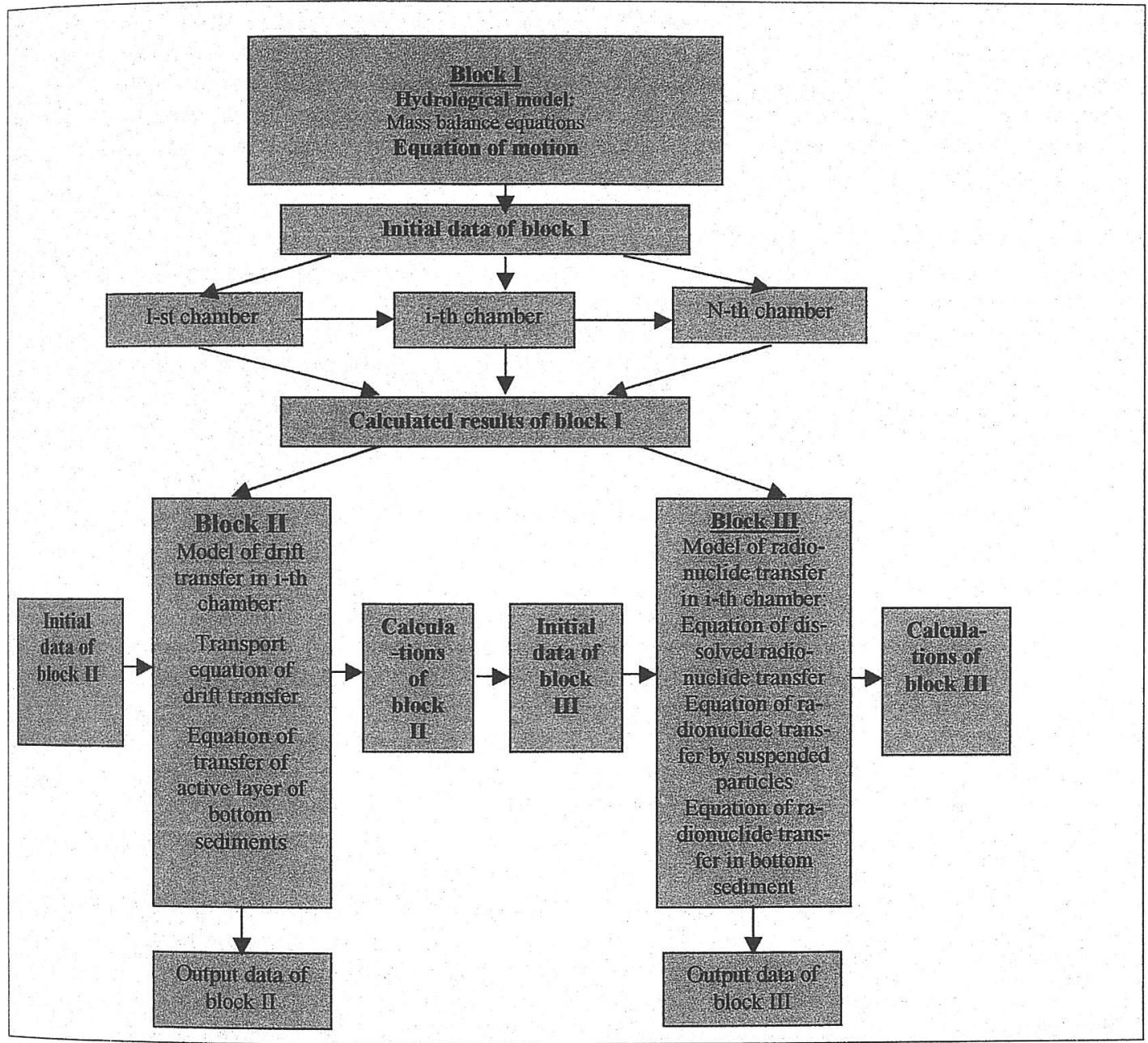

Fig.1. Flow chart for calculation of radionuclide transfer in river system.

\subsection{The forecast estimations of radioactive contamination spread in the rivers}

Using this model were made the short- term and the long-term forecasts of radioactive situation changes on the Iput river.

The long-term forecasts was prepared till 2080. There is an assumption that contamination of the river system at this time will be determined only by radionuclide access with hard and liquid surface runoff from the water catchment. According to this forecast in this period will be observed gradual decrease of ${ }^{137} \mathrm{Cs}$ concentration in the water, on suspensions and in bottom sediments in average within one point. Thus, in the sampling site in Dobrush they will change within the range: in soluble forms -28 $-3,6 \mathrm{~Bq} / \mathrm{m}^{3}$, on suspensions $-11,6-1,5 \mathrm{~Bq} / \mathrm{m}^{3}$, in bottom sediments $-261-34,3 \mathrm{~Bq} / \mathrm{kg} ;{ }^{137} \mathrm{Cs}$ concentration on suspensions and in bottom sediments in Dobrush sampling site can be lower than in the sites of upper reaches. Thus, even in 2080 it will be important to hold radiation monitoring. 


\subsection{Trans-border radionuclide transfer}

For studying of the peculiarities of radioactive contamination formation of the Iput on the territory of Belarus and Russia was held the study of ${ }^{137} \mathrm{Cs}$ trans-border transfer, using the model.

The river Iput flows mainly on the territory of Russia ( $-90 \%)$. Its runoff almost for $95 \%$ is formed on this territory. That is why there is a strong influence of trans-border radionuclide transfer from the territory of Russia on the Iput contamination on the territory of Belarus. For the detection of the contribution, made by trans-border transfer, into the Iput on the territory of Belarus were made the calculations which assume that the access of contamination into the river network in five last parts of the river bed in Belarus and in five first in Russia is interchangeably missed.

The results of this research show that in Dobrush sampling site during the first year after the ChNPP accident the maximum radionuclide concentration in water was determined by the direct fallout of radioactive aerosols on the water surface of the rivers in Belarus. By the end of 1986 contamination contribution of the Iput from the territories of Belarus reduced from $100 \%$ to $\sim 70 \%$ in the last sampling site, and from 1987 till 2000 its value did not accede $14 \%$.

Thus, at present $\sim 86 \%$ of ${ }^{137} \mathrm{Cs}$ contamination of the Iput accesses from the territory of Russia andin spite of the fact that the contamination density of the watershed area of the Iput in Belarus is much higher than in Russia, the water contamination is mainly determined by trans-border transfer. The determining factor in this case is the formation of the main share of the river runoff on the territory of Russia and huge ${ }^{137} \mathrm{Cs}$ store on the watershed territory in Russia $\sim 1.9 \cdot 10^{15} \mathrm{~Bq}$, against $\sim 5.6 \cdot 10^{14} \mathrm{~Bq}$ in Belarus.

\section{CONCLUSIONS}

- 15 years after the ChNPP accident there was a significant decrease of ${ }^{137} \mathrm{Cs}$ and ${ }^{90} \mathrm{Sr}$ concentrationin surface water of the rivers, however water contamination levels by these radionuclides are still higher than those pre accidental.

- At present ${ }^{137} \mathrm{Cs}$ is washed out from the water catchment areas and is transported along the bed of the rivers in the greater degree with hard particles, and ${ }^{90} \mathrm{Sr}$ migrates mostly in soluble state.

- The contribution of large watershed areas with low levels of radioactive contamination into the formation of the river runoff has more influence on the secondary contamination than the surface washoff from a very contaminated territories but with relatively small watershed areas.

- The worked out mathematical model of radionuclide transfer by river allows to obtain short-term and long-term forecasts of radiation situation on the rivers, and also to give estimation to the trans-border transfer of radionuclides by water.

\section{References}

1. Vakulovskii S.M., Nikitin A.I.and ChumichevV.B. Contamination of water objects by ${ }^{137} \mathrm{Cs}$ and ${ }^{9 \mathrm{St}}$ on the territories subjected to the influence of ejections from the ChNPP, Meteorology and hydrology. (1991, №7) 64-73.

2. Voitsekhovitch O.V. Radiogeoecology of water objects of the zone of influence of the ChNPP accident. Vol.1. (Chernobylinterinform, Kiev, 1997) pp. 82-85.

3. Zhukova O.M., Matveenko I.I., Shagalova E.D., Shiryaeva N.M., Myshkina N.K. "Dynamics of radioactive contamination of rivers in Belarus", Conf. Radioactivity during nuclear explosions and accidents, Moscow, 24-26 April, 2000 (Hydrometizdat, St. Petersburg, 2000) pp. 680-684.

4. Voitsekhovitch O.V., Kanivets I.I., Laptev G.V. Analysis of radioactine contamination formation of the Dnieper system for 5 years after the ChNPP accident Trudy UkrNIGMI. (1993, №245) 106-127.

5. Zhukova O.M., Matveenko I.I., Myshkina N.K., Sharovarov G. A. Shiryaeva N.M. Formation and dynamics of distribution of radioactive contamination in the rivers of Belarus after the ChNPP accident. Technical magazine. (1997, Vol. 70, №1) 73-81. 